Check for updates

Cite this: RSC Adv., 2017, 7, 32952

\title{
Fluorescent microsphere immunochromatographic assays for detecting bone alkaline phosphatase based on biolayer interferometry-selected antibody $\dagger$
}

\author{
Miao Liu, (DD a Li-Feng Zeng, ${ }^{b}$ Ya-Jie Yang, ${ }^{a}$ Li-Ming Hu ${ }^{a}$ and Wei-Hua Lai ${ }^{* a}$
}

Bone alkaline phosphatase (BAP) is commonly used as a clinical marker for diagnosing and monitoring overall metabolic bone disease. In this study, a convenient, reliable, highly sensitive, and competitive fluorescent microsphere-lateral flow immunochromatographic assay (FM-LFIA) was developed for the quantitative detection of BAP for the first time. The antibody (ab17272) with the minimum equilibrium dissociation constant $\left(K_{\mathrm{D}}, K_{\mathrm{D}}=1.503 \times 10^{-8} \mathrm{M}\right)$ used in FM-LFIA was selected by the biolayer interferometry system. Various parameters that influence the FM-LFIA were optimized. Under the optimized conditions, the limit of detection for BAP was $0.1 \mathrm{ng} \mathrm{mL} \mathrm{m}^{-1}$ within $15 \mathrm{~min}$ with a good linear range of $0.1 \mathrm{ng} \mathrm{mL}^{-1}$ to $250.0 \mathrm{ng} \mathrm{mL}^{-1}$. The average recoveries for intra- and inter-assays ranged from $98.6 \%$ to $103.8 \%$ and $92.4 \%$ to $111.5 \%$ with corresponding CVs of $6.7 \%$ to $8.5 \%$ and $4.6 \%$ to $9.3 \%$, respectively. The test strips showed satisfactory stability through an accelerated aging test at $60{ }^{\circ} \mathrm{C}$ for 6 days. Owing to its high sensitivity and simplicity, FM-LFIA can be easily used to rapidly detect BAP.

Received 1st April 2017

Accepted 22nd June 2017

DOI: $10.1039 / \mathrm{c} 7 \mathrm{ra03756b}$

rsc.li/rsc-advances and skilled operators, which are unsuitable for the rapid and convenient clinical detection of BAP.

Lateral flow immunochromatographic assay (LFIA) ${ }^{19}$ is a rapid analytical technique with several advantages such as simplicity, speediness, and sensitiveness. The technique combines immunochromatographic procedure, label technique, and antigen-antibody properties to provide rapid detection of various analytes in different field, such as human chorionic gonadotropin (HCG) detection in biomedicine, ${ }^{20}$ pathogens in food safety, ${ }^{21}$ and metal ions in environmental monitoring. ${ }^{22}$ In the LFIA, labels lay the foundation for improving limit of detection (LOD) because of their unique properties, such as optical absorption, fluorescence spectra, and magnetic properties. Colloidal gold (CG ${ }^{23,24}$ is considered as one of the most widely used optical label in the LFIA. The CG has a vivid red color for qualitative detection by naked eye or quantitative detection by strip reader. ${ }^{25}$ However, colloidal goldlateral flow immunochromatographic assay (CG-LFIA) shows serious limitations when high sensitivity is needed. Various novel labels, including magnetic nanoparticles, ${ }^{26,27}$ quantum dots, ${ }^{28,29}$ and fluorescent microspheres $(\mathrm{FMs})^{30}$ are recently used in LFIA to improve LOD.

FMs are polystyrene materials that contain dyes in the interior of the bead, thereby producing a stable configuration, unique luminescent properties. Because of these properties, FMs have already been used as label to detect analytes in food safety $^{31}$ and medical diagnostics. ${ }^{32}$ Comparative evaluations between FMs and CG in the LFIA have been reported, the results
${ }^{a}$ State Key Laboratory of Food Science and Technology, Nanchang University, 235 Nanjing East Road, Nanchang 330047, China. E-mail: talktolaiwh@163.com; Fax: +86791 88333708; Tel: +86 13879178802

${ }^{b}$ Department of Clinical Laboratory, Jiangxi Provincial People's Hospital, Nanchang 330006, China

$\dagger$ Electronic supplementary information (ESI) available. See DOI: 10.1039/c7ra03756b 
showed that the FM-LFIA has advantages over CG-LFIA in terms of sensitivity, coefficient of variation (CV), and antibody needed. ${ }^{33}$ Herein, FMs were used as the label in LFIA for BAP detection in this study.

Biolayer interferometry (BLI $)^{34,35}$ is a technique that analyzes the changes in an interference pattern generated from the visible light that is reflected from the two surfaces. BLI is commonly used as the tool to measure and evaluate the binding affinity between biomolecules. $^{35,36}$ In this study, a novel competitive FM-LFIA was first developed for the rapid detection of BAP concentration. BLI was used to select the anti-BAP antibody with highest binding affinity to BAP.

\section{Experimental section}

\subsection{Reagents}

The fluorescein isothiocyanate FMs (1\%, solid content, w/v; excitation $=470 \mathrm{~nm}$, emission $=525 \mathrm{~nm}$ ) were purchased from Merck Company (Darmstadt, Germany). BAP human antigen was provided by Beijing Zhongsheng Jinyu Diagnosis Technology Co., Ltd. (Beijing, China). Mouse anti-human BAP monoclonal antibody (mAb, ab17272) and sheep anti-human BAP polyclonal antibody (pAb, ab68716) were obtained from Abcam Company (Cambridge, UK). Sheep anti-human BAP pAb (P4071-11B) was obtained from US Biological Company (Santiago, US). Sheep anti-human BAP pAb (0578G) was purchased from AbD Serotec Company (Oxford, UK). Sheep anti-human BAP pAb (55816) was purchased from Chemtura Corporation (New York, US). Rabbit anti-human BAP pAb (Tu3) was prepared in our laboratory. Goat anti-mouse IgG was obtained from Beijing Zhongshan Biotechnology Inc. (Beijing, China). Streptavidin-coated sensor was provided by Pall ForteBio Llc. (California, USA). Nitrocellulose membrane (NC membrane) was supplied by Millipore (Bendford, MA, USA). Polyvinylchloride backing pad, absorbent pad, sample pad, and conjugate pad were purchased from Shanghai Kinbio Tech. Co., Ltd. (Shanghai, China). Prealbumin (PA) was provided by GenWay Biotech, Inc. (San Diego, USA). Artificial serum was obtained from Huzhou InnoReagents Co.,Ltd. (Zhejiang, China) Intestinal mucosa alkaline phosphatase (IALP), human placental alkaline phosphatase (PALP), hemoglobin (HGB), albumin (ALB) from human serum, 2-( $N$-morpholino)ethanesulfonic acid (MES), $N$-(3-dimethylaminopropyl)- $N$-ethylcarbodiimide hydrochloride (EDC), and bovine serum albumin (BSA) were obtained from Sigma (St. Louis, MO, USA). Other reagents were of analytical grade and purchased from Sinopharm Chemical Corp. (Shanghai, China).

\subsection{Apparatus}

The F-380 fluorescence spectrophotometer was supplied by Tianjin Gangdong Sci. \&Tech Development Co., Ltd. (Tianjin, China). The fluorescence strip reader (excitation $=470 \mathrm{~nm}$, emission $=525 \mathrm{~nm}$ ) was obtained from Suzhou Helmen Precision Instrument Co., Ltd. (Suzhou, China). The Multiskan spectrum microplate reader was purchased from Thermo Fisher Scientific Inc. (Massachusetts, USA). BioDot XYZ platform combined with a motion controller, BioJet Quanti3000k dispenser, and AirJet Quanti3000k dispenser were purchased from BioDot (Irvine, CA, USA). Vacuum drying oven was obtained from Shanghai Fuma Test Equipment Co., Ltd. (Shanghai, China). The automatic guillotine cutter was purchased from Hangzhou Fenghang Technology Co., Ltd. (Hangzhou, China). The BLItz ${ }^{\circledR}$ system was provided by Pall ForteBio Llc. (California, USA).

\subsection{Antibody binding kinetics analysis}

In this system, the binding affinity between BAP and six antiBAP antibodies (anti-BAP Abs): ab17272, Tu3, ab68716, 0578G, 55816, and 11B was measured by BLI using a BLItz ${ }^{\circledR}$ System. In a typical BLI experiment, each assay was involved in two committed steps: an association step where the specific binding transpired and a dissociation step where the bound antibody was removed (Fig. $\mathrm{S} 1 \dagger$ ). The assay was adapted from previous literature. ${ }^{35}$ Briefly, $4 \mu \mathrm{L}$ of biotinylated BAP $(25 \mu \mathrm{g}$ $\mathrm{mL}^{-1}$ ) were pre-immobilized on the tip surface of streptavidincoated sensors in phosphate buffer saline (PBS) for $120 \mathrm{~s}$. Unbound biotinylated BAP were removed from the surface of the sensors by incubation in PBS buffer for $60 \mathrm{~s}$. Next, the streptavidin-coated sensors containing immobilized biotinylated BAP were incubated with $4 \mu \mathrm{L}$ of increasing concentrations $\left(6,12,25\right.$, and $\left.50 \mu \mathrm{g} \mathrm{mL}^{-1}\right)$ of anti-BAP Abs for $300 \mathrm{~s}$ (association). In this step, the binding interaction of the anti-BAP Abs to the immobilized BAP was measured. After association step, the sensors were dipped into PBS buffer without anti-BAP Abs for $300 \mathrm{~s}$, and the bound anti-BAP Abs were allowed to come off the BAP (dissociation). The binding response was measured in real time on a sensorgram. The association constant (on-rate, $K_{\mathrm{on}}$ ), dissociation constant (offrate, $\left.K_{\text {off }}\right)$, and equilibrium dissociation constant $\left(K_{\text {off }} / K_{\text {on }}, K_{\mathrm{D}}\right)$ were calculated by the built-in BLItz software as a $1: 1$ binding model (the relationship between $K_{\text {on }}, K_{\text {off }}, K_{\mathrm{D}}$, and $1: 1$ binding model are shown in the ESI†).

\subsection{Preparation and characterizations of FM-mAb conjugates}

FM-mAb conjugates were prepared according to a previous paper: ${ }^{37} 0.15 \mathrm{mg}$ FMs and $15 \mu \mathrm{L}$ of freshly prepared aqueous solution of EDC were slowly added to $3.0 \mathrm{~mL}$ of $0.05 \mathrm{M}$ MES buffer ( $\mathrm{pH}=5.0,6.0,7.0,8.0,9.0)$. After 1 min sonication, $15 \mu \mathrm{L}$ of anti-BAP mAb $\left(10,20,30\right.$, and $\left.50 \mu \mathrm{g} \mathrm{mg}^{-1}\right)$ was drop-wise added. The solution was incubated at room temperature for $2 \mathrm{~h}$ and then blocked with $300 \mu \mathrm{L}$ of $10 \% \mathrm{BSA}(\mathrm{w} / \mathrm{v})$ for $30 \mathrm{~min}$. The mixture was centrifuged at $9000 \mathrm{rpm}$ for $10 \mathrm{~min}$. The final FM-mAb conjugates were dissolved in $300 \mu \mathrm{L}$ of solution containing $0.02 \mathrm{M} \mathrm{Na}_{2} \mathrm{HPO}_{4}(\mathrm{pH} 5.5$ ), 5\% sucrose (w/v), 3\% trehalose (w/v), 0.1\% $\mathrm{NaN}_{3}, 1 \%$ BSA (w/v), and 1\% Tween-20 (v/v). Resuspended FM-mAb conjugates were stored at $4{ }^{\circ} \mathrm{C}$ in the dark for further use. FMs and FM-mAb conjugates were analyzed using the F-380 fluorescence spectrophotometer and Multiskan spectrum microplate reader. 


\subsection{Preparation of the FM-LFIA test strip}

Fig. 1A shows the structure of FM-LFIA strip, which is composed of sample pad, conjugate pad, nitrocellulose membrane (NC membrane), and absorbent pad. The sample pad was soaked for $3 \mathrm{~min}$ with $20 \mathrm{mM}$ phosphate buffer containing $0.5 \% \mathrm{PVP}(\mathrm{w} / \mathrm{v})$, $3 \%$ sucrose, $1 \%$ BSA, $0.5 \%$ Tween-20 (v/v), and $0.1 \% \mathrm{NaN}_{3} \cdot{ }^{33,38}$ The sample pad was dried at $60{ }^{\circ} \mathrm{C}$ for $2 \mathrm{~h}$. The conjugate pad was pretreated with $20 \mathrm{mM}$ phosphate buffer with $1 \% \mathrm{BSA}, 0.5 \%$ Tween-20 (v/v), and $0.1 \% \mathrm{NaN}_{3}$ and was dried at $37^{\circ} \mathrm{C}$ for $12 \mathrm{~h}$. $\operatorname{BAP}\left(1.0,2.0\right.$, and $\left.4.0 \mathrm{mg} \mathrm{mL}^{-1}\right)$ and goat anti-mouse IgG (0.10, 0.25 , and $0.50 \mathrm{mg} \mathrm{mL}^{-1}$ ) were subsequently sprayed onto the NC membrane as the test line ( $\mathrm{T}$ line) and control line (C line), respectively.

\subsection{Immunoassay procedure}

As shown in Fig. 1B, the immunoassay procedure was performed as follows: FM-mAb conjugates $(1.0,2.0$, and $3.0 \mu \mathrm{L})$ and $100 \mu \mathrm{L}$ of specimens diluted by MES buffer were added into the ELISA well and incubated for $3 \mathrm{~min}$. Subsequently, the complex solution was pipetted to the sample pad of the FM-LFIA test strip. After 15 min, the FM-LFIA test strip was placed in the fluorescence strip reader. The fluorescence intensity of the $\mathrm{T}$ line $\left(\mathrm{FI}_{\mathrm{T}}\right)$, fluorescence intensity of the $\mathrm{C}$ line $\left(\mathrm{FI}_{\mathrm{C}}\right)$, and the $\mathrm{FI}_{\mathrm{T}}$ / $\mathrm{FI}_{\mathrm{C}}$ ratio were recorded with the fluorescence strip reader. The results of the $\mathrm{T}$ line and $\mathrm{C}$ line could be also observed by naked eye under a UV light with the excitation wavelength of $470 \mathrm{~nm}$. When there were no BAP in the specimens (negative), all FMmAb conjugates moved along the NC membrane by capillary and were captured by BAP immobilized on the $\mathrm{T}$ line, which caused the highest intensity of fluorescence. Once the specimens contain BAP (positive), BAP would react with its corresponding FM-mAb conjugates in the ELISA well. Later, the un-reacted FM-mAb conjugates were captured by BAP immobilized on the $\mathrm{T}$ line, which lead to fluorescence intensity on the $\mathrm{T}$ line changing from strong to weak with increasing concentration of BAP. The FM-mAb conjugates should be captured by goat anti-mouse IgG on the $\mathrm{C}$ line regardless of the presence of BAP (Fig. 1C).

\subsection{Immunological kinetics analysis of the test strip}

The kinetic analysis of FM-mAb conjugates and antigen (BAP on the $\mathrm{T}$ line and goat anti-mouse IgG on the $\mathrm{C}$ line) interaction was conducted as follows: $2.0 \mu \mathrm{L}$ of FM-mAb conjugates and 100 $\mu \mathrm{L}$ of specimens $\left(0,5,30\right.$, and $\left.100 \mathrm{ng} \mathrm{mL} \mathrm{m}^{-1}\right)$ were added into the ELISA well and incubated for $3 \mathrm{~min}$. The $\mathrm{FI}_{\mathrm{T}}$ and $\mathrm{FI}_{\mathrm{C}}$ were recorded every $1 \mathrm{~min}$ for $35 \mathrm{~min}$. The kinetics reaction curve between the FM-mAb conjugates and the BAP on the T line, as well as those of the FM-mAb conjugates and the goat antimouse IgG on the $\mathrm{C}$ line, were established by plotting the $\mathrm{FI}_{\mathrm{T}} /$ $\mathrm{FI}_{\mathrm{C}}$ against the immunoreaction time.

\subsection{Quantitative standard curve of the FM-LFIA test strip}

The standard BAP solutions were diluted to final concentrations of $0.000,0.005,0.050,0.100,0.500,5.000,10.000,100.000$, 250.000 , and $500.000 \mathrm{ng} \mathrm{mL}^{-1}$ in artificial serum and were detected by the FM-LFIA test strip. The $\mathrm{FI}_{\mathrm{T}} / \mathrm{FI}_{\mathrm{C}}$ ratios between the negative and positive samples were defined as $B_{0}$ and $B$, respectively. The standard curve was constructed by plotting the $B / B_{0}$ ratios against the logarithm of different BAP concentrations. Each spiked concentration of the standard solutions was

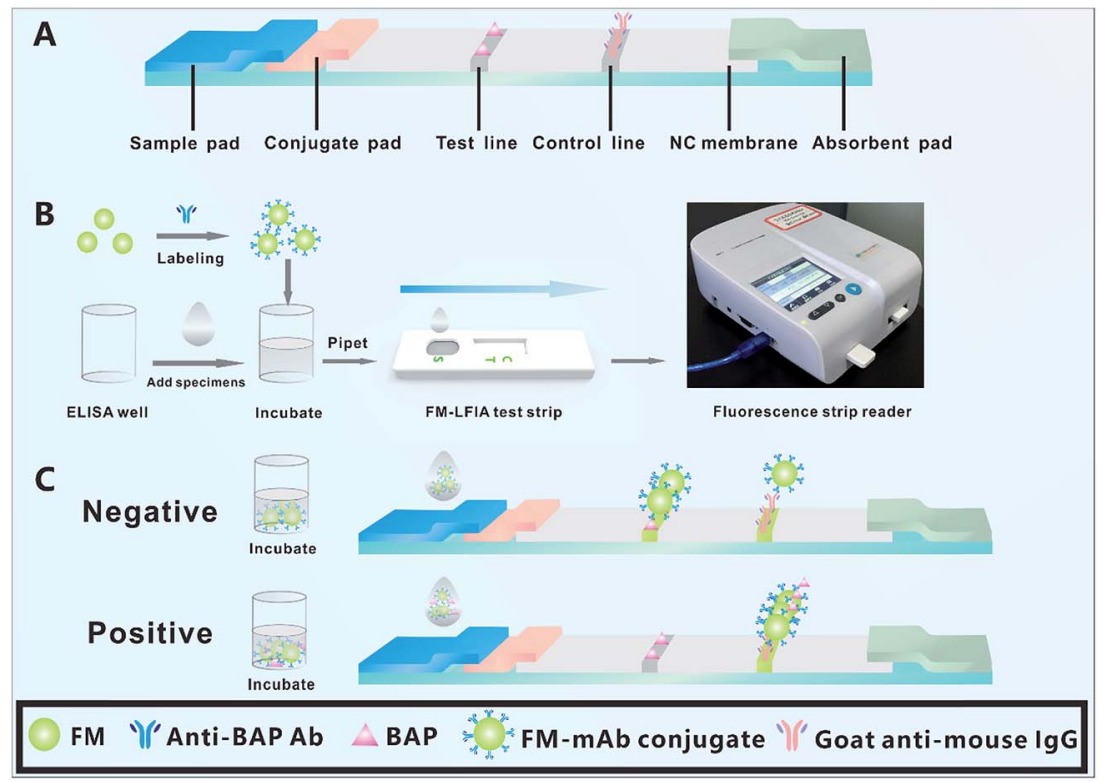

Fig. 1 The structure chart and principle of FM-LFIA test strip. When there was no BAP in the specimens (negative), FM-mAb conjugates moved along the NC membrane by capillary and were captured by BAP immobilized on the T line, which had the highest intensity of fluorescence. Once the specimens contain BAP (positive), BAP would react with FM-mAb conjugates in the ELISA well. Later, the un-reacted FM-mAb conjugates were captured by BAP immobilized on the $T$ line, which had decreasing fluorescence intensity with increasing concentration of BAP. 
performed in triplicate. LOD was defined as the concentration of BAP which was based on the average $\mathrm{FI}_{\mathrm{T}} / \mathrm{FI}_{\mathrm{C}}$ of negative samples minus threefold standard deviations from the average. ${ }^{39}$

\subsection{Specificity of the FM-LFIA test strip}

The specificity was studied using BAP, IALP, PALP, PA, HGB, and ALB in a concentration of $500 \mathrm{ng} \mathrm{mL}^{-1}$. Each measurement was performed in triplicate.

\subsection{Accuracy and precision analysis}

The accuracy and precision of the FM-LFIA were evaluated by analyzing the recovery and CVs of the intra- and inter-assays with adding three concentrations $\left(5,50\right.$, and $\left.150 \mathrm{ng} \mathrm{mL} \mathrm{m}^{-1}\right)$ of BAP to the artificial serum. The intra-assays were completed as follows: three concentrations $\left(5,50\right.$, and $\left.150 \mathrm{ng} \mathrm{mL}{ }^{-1}\right)$ of BAP were tested on the same batches of FM-LFIA test strips within 1 day, each concentration of BAP was repeated 3 times. The interassays were analyzed as follows: three concentrations $(5,50$, and $150 \mathrm{ng} \mathrm{mL}{ }^{-1}$ ) of BAP were tested on 3 batches of FM-LFIA test strips within 3 day, each concentration of BAP was repeated 3 times on each batch. The CVs of intra- and inter-assays were calculated.

\subsection{Accelerated aging test at $60{ }^{\circ} \mathrm{C}$}

The prepared strips were placed in a drying oven at $60{ }^{\circ} \mathrm{C}$ for 13 days. $\mathrm{FI}_{\mathrm{T}}, \mathrm{FI}_{\mathrm{C}}$, and $\mathrm{FI}_{\mathrm{T}} / \mathrm{FI}_{\mathrm{C}}$ ratio values of these test strips were recorded every day. Each measurement was performed in triplicate.

\section{Results and discussion}

\subsection{Screening the optimal anti-BAP antibody}

The binding affinity between BAP and six anti-BAP antibodies of different concentration was measured by BLI using a BLItz ${ }^{\circledR}$ System. The sensorgram curves are shown in Fig. 2, and the $K_{\mathrm{D}}$ was calculated as the $K_{\text {on }}$ divided by the $K_{\text {off }}$ (Table 1 ). In Fig. 2 , the signal of interference was enhanced with the increasing concentrations $\left(3,6,12,25\right.$, and $\left.50 \mu \mathrm{g} \mathrm{mL} \mathrm{m}^{-1}\right)$ of the anti-BAP antibody. The antibodies showed different binding affinities to BAP. The maximal association constant $\left(K_{\text {on }}=3.17 \times 10^{4}\right.$ $\mathrm{M}^{-1} \mathrm{~s}^{-1}$ ) was found between BAP and anti-BAP antibody (ab17272). The minimum dissociation constant $\left(K_{\text {off }}=3.048 \times\right.$ $10^{-4} \mathrm{~s}^{-1}$ ) of anti-BAP antibody (11B) is shown in Table 1. Although the dissociation constant $\left(K_{\text {off }}=4.765 \times 10^{-4} \mathrm{~s}^{-1}\right)$ of ab17272 was higher than that of $11 \mathrm{~B}$, the calculated $K_{\mathrm{D}}\left(K_{\mathrm{D}}=\right.$ $\left.1.503 \times 10^{-8} \mathrm{M}\right)$ of ab17272 was still the minimum among the six anti-BAP antibodies. These data indicated that ab17272 with the minimum $K_{\mathrm{D}}$ possesses the highest affinity towards BAP. The antibody with high affinity could efficiently capture BAP and maintain a stable BAP-Ab complex. In the competitive assay, only one antibody was required, the anti-BAP antibody possessing highest binding affinity with BAP should be used for immunization to achieve a higher competitive inhibition ratio. $^{\mathbf{4 0 , 4 1}}$ Compared with other anti-BAP antibodies, the ab17272 exhibited the minimum $K_{\mathrm{D}}$. Therefore, the anti-BAP $\mathrm{mAb}$ (ab17272) was selected for the FM-LFIA.

\subsection{Characterization of FMs and FM-mAb conjugates}

It was a key factor in FM-LFIA whether anti-BAP mAb was successfully coupled on the FMs surface. Fluorescence Spectra and UV-vis absorption spectra were often used as the
A



D

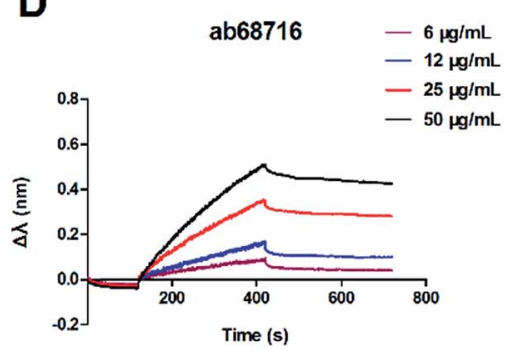

B

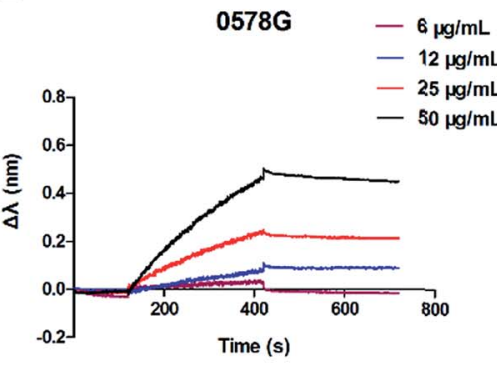

E

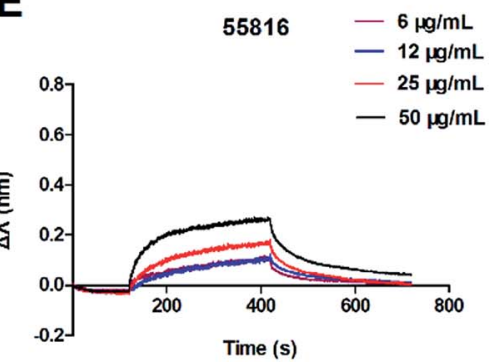

C



$\mathbf{F}$

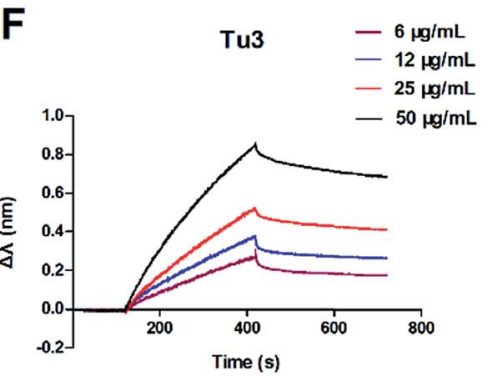

Fig. 2 Sensorgram for the interaction between six anti-BAP antibodies and BAP. The sensorgram obtained via BLI with increasing concentrations $\left(6,12,25\right.$, and $50 \mu \mathrm{g} \mathrm{mL}^{-1}$ ) of six anti-BAP antibodies including (A) ab17272, (B) 0578G, (C) 11B, (D) ab68716, (E) 55816, and (F) Tu3. 
Table 1 Characterization of $K_{\mathrm{D}}$ values for BAP and different anti-BAP Abs using BLItz® system

\begin{tabular}{llll}
\hline Antibody & $K_{\text {on }}\left(\mathrm{M}^{-1} \mathrm{~s}^{-1}\right)$ & $K_{\text {off }}\left(\mathrm{s}^{-1}\right)$ & $K_{\mathrm{D}}(\mathrm{M})$ \\
\hline ab17272 & $3.17 \times 10^{4}$ & $4.765 \times 10^{-4}$ & $1.503 \times 10^{-8}$ \\
0578G & $4.592 \times 10^{3}$ & $5.345 \times 10^{-4}$ & $1.164 \times 10^{-7}$ \\
11B & $6.001 \times 10^{3}$ & $3.048 \times 10^{-4}$ & $5.079 \times 10^{-8}$ \\
ab68716 & $3.794 \times 10^{3}$ & $7.235 \times 10^{-4}$ & $1.907 \times 10^{-7}$ \\
55816 & $4.334 \times 10^{3}$ & $5.912 \times 10^{-4}$ & $1.364 \times 10^{-7}$ \\
Tu3 & $3.878 \times 10^{3}$ & $9.297 \times 10^{-4}$ & $2.397 \times 10^{-7}$
\end{tabular}

characterizing methods to confirm the result of labeling process. $^{42}$ F-380 fluorescence spectrophotometer was used to characterize the fluorescence properties of free FMs and FM-
mAb conjugates. The maximum emission peaks of FM-mAb conjugates and free FMs were observed in a similar position. However, the fluorescence intensities of FM-mAb conjugates decreased compared with those of the FMs alone (Fig. 3A) because a portion of the fluorescence signal was shielded by the antibody on the FM surface. The characteristic absorption peaks of anti-BAP antibody (ab17272), FMs, and FM-mAb conjugates are displayed in Fig. 3B. The spectra of FMs and Anti-BAP mAb had characteristic absorption peaks at 240 and $280 \mathrm{~nm}$, respectively. The spectrum of the FM-mAb conjugate had characteristic absorption peaks at 240 and $280 \mathrm{~nm}$, which confirmed that the antibody (ab17272) was successfully coupled to the FMs.

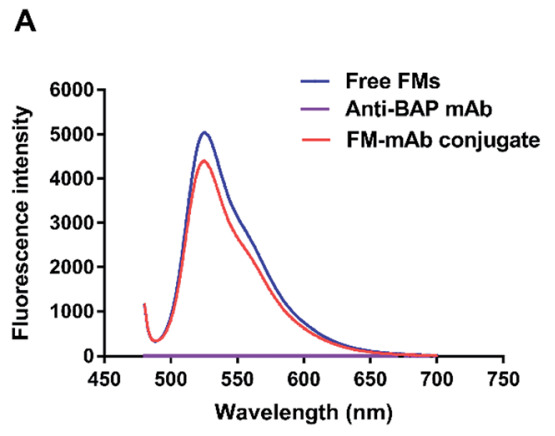

B

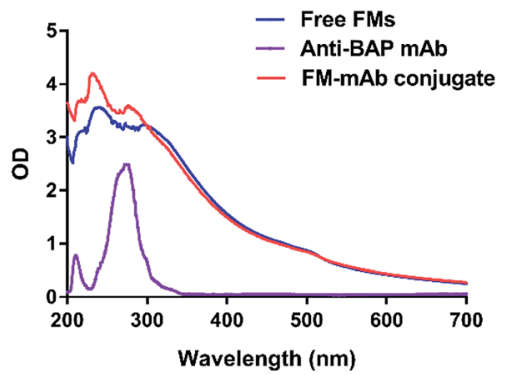

Fig. 3 (A). Fluorescence intensities of free FMs, anti-BAP mAb and FM-mAb conjugates. (B). Ultraviolet visible spectra of FMs, anti-BAP mAb and FM-mAb conjugates.

A

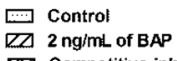

区 Competitive inhibition ratio

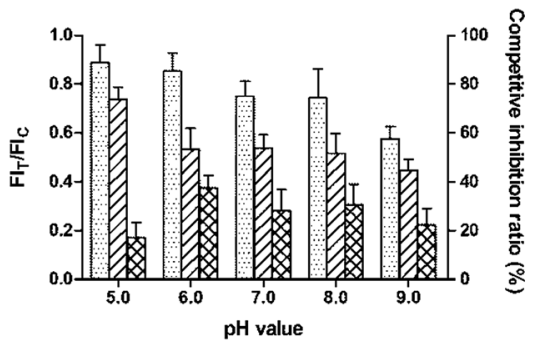

C

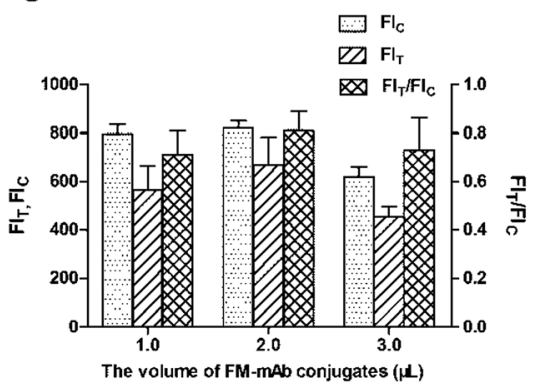

B

Control

एل $2 \mathrm{ng} / \mathrm{mL}$ of BAP

¿x Competitive inhibition ratio

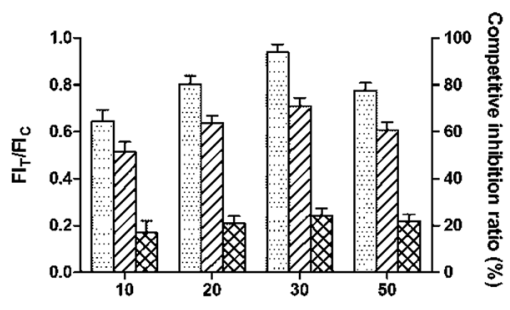

The concentration of anti-BAP mAb ( $/ \mathrm{g} / \mathrm{mg})$

D

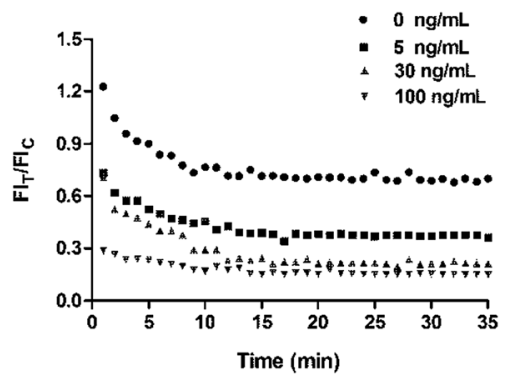

Fig. 4 Effects of $\mathrm{pH}$ value, the concentration of anti-BAP mAb on labeling process, the volumes of FM-mAb conjugates, and immunoreaction time on the FM-LFIA. (A) Different $\mathrm{pH}$ values $\left(5.0,6.0,7.0,8.0\right.$, and 9.0), (B) different concentrations of anti-BAP $\mathrm{mAb}\left(10,20,30\right.$, and 50 $\mu \mathrm{g} \mathrm{mg}{ }^{-1}$ ), (C) different volumes $\left(1.0,2.0\right.$, and $3.0 \mu \mathrm{L}$ ) of $\mathrm{FMs}-\mathrm{mAb}$ conjugates, and $(\mathrm{D})$ immunoreaction dynamics of $\mathrm{FI}_{\mathrm{T}} / \mathrm{FI}_{\mathrm{C}}$ ratio with different $\mathrm{BAP}$ concentrations $\left(0,5,30\right.$, and $\left.100 \mathrm{ng} \mathrm{mL}^{-1}\right)$ of the sample. Data were obtained from three replicates. 


\subsection{Optimization of experiment conditions}

The labeling $\mathrm{pH}$ and concentration of anti-BAP mAb both affect the antibody activity and coupling efficiency in labeling process. ${ }^{43}$ The optimal labeling $\mathrm{pH}$ and concentration of antiBAP mAb were determined by comparing the $\mathrm{FI}_{\mathrm{T}} / \mathrm{FI}_{\mathrm{C}}$ ratio of the negative samples and the competitive inhibition ratio of the positive samples. The competitive inhibition ratio was defined as $\left(1-B / B_{0}\right)$, and the $\mathrm{FI}_{\mathrm{T}} / \mathrm{FI}_{\mathrm{C}}$ ratios between the negative and positive samples $\left(2.0 \mathrm{ng} \mathrm{mL}^{-1}\right)$ were defined as $B_{0}$ and $B$, respectively. In Fig. $4 \mathrm{~A}$, the $\mathrm{FI}_{\mathrm{T}} / \mathrm{FI}_{\mathrm{C}}$ ratio of negative samples slightly decreased with the increased $\mathrm{pH}$, a strong $\mathrm{FI}_{\mathrm{T}} / \mathrm{FI}_{\mathrm{C}}$ ratio was observed at $\mathrm{pH}$ 6.0. The maximum competitive inhibition ratio $(37.53 \%)$ of positive samples was also observed at $\mathrm{pH}$ 6.0. Therefore, pH 6.0 is the optimal pH for coupling with FMs. ${ }^{44}$ Similarly, the maximum competitive inhibition ratio $(24.21 \%)$ of positive samples was obtained at $30 \mu \mathrm{g} \mathrm{mg} \mathrm{g}^{-1}$ of anti-BAP $\mathrm{mAb}$. The $\mathrm{FI}_{\mathrm{T}} / \mathrm{FI}_{\mathrm{C}}$ ratio of the negative samples gradually increased with the increasing concentrations $(10,20$, and $30 \mu \mathrm{g}$ $\mathrm{mg}^{-1}$ ) of anti-BAP $\mathrm{mAb}$, the highest ratio of 0.938 was obtained at $30 \mu \mathrm{g} \mathrm{mg}^{-1}$ (Fig. 4B). The $\mathrm{FI}_{\mathrm{T}} / \mathrm{FI}_{\mathrm{C}}$ ratio of the negative samples decreased at $50 \mu \mathrm{g} \mathrm{mg}{ }^{-1}$ compared with that at $30 \mu \mathrm{g} \mathrm{mg}{ }^{-1}$, presumably due to the inappropriate ratio between the FMs and anti-BAP mAb. The coupling rate between the FMs and antibody is not always positively correlated with the concentration of antibody. The distance between the antibodies on the surface of FMs narrowed with the increasing concentration of antibody. If the antibodies attached to FMs were excessive, then antibodyantibody interactions cause steric hindrance. Therefore, $30 \mu \mathrm{g}$ $\mathrm{mg}^{-1}$ is the optimal concentration of anti-BAP mAb for coupling with FMs.

In addition, the sensitivity of the FM-LFIA is affected by some other parameters, including the additive amount of FM-mAb conjugates, the concentration of BAP and goat anti-mouse IgG on the $\mathrm{T}$ line and $\mathrm{C}$ line respectively, and the kinetic reaction time. As shown in Fig. $4 \mathrm{C}$, the highest $\mathrm{FI}_{\mathrm{T}} / \mathrm{FI}_{\mathrm{C}}$ ratio $(0.811)$ of negative samples was recorded with $2 \mu \mathrm{L}$ of FM-mAb conjugates. After applying all of the optimized parameters, the reaction time was determined by the samples spiked with different BAP concentrations $\left(0,5,30\right.$, and $\left.100 \mathrm{ng} \mathrm{mL}^{-1}\right)$. The $\mathrm{FI}_{\mathrm{T}} / \mathrm{FI}_{\mathrm{C}}$ ratio of different $\mathrm{BAP}$ concentrations both gradually decreased with the reaction time and reached a constant value at $15 \mathrm{~min}$ after the sample addition (Fig. 4D). Therefore, $15 \mathrm{~min}$ of immunoreaction time is required for the FM-LFIA.
A
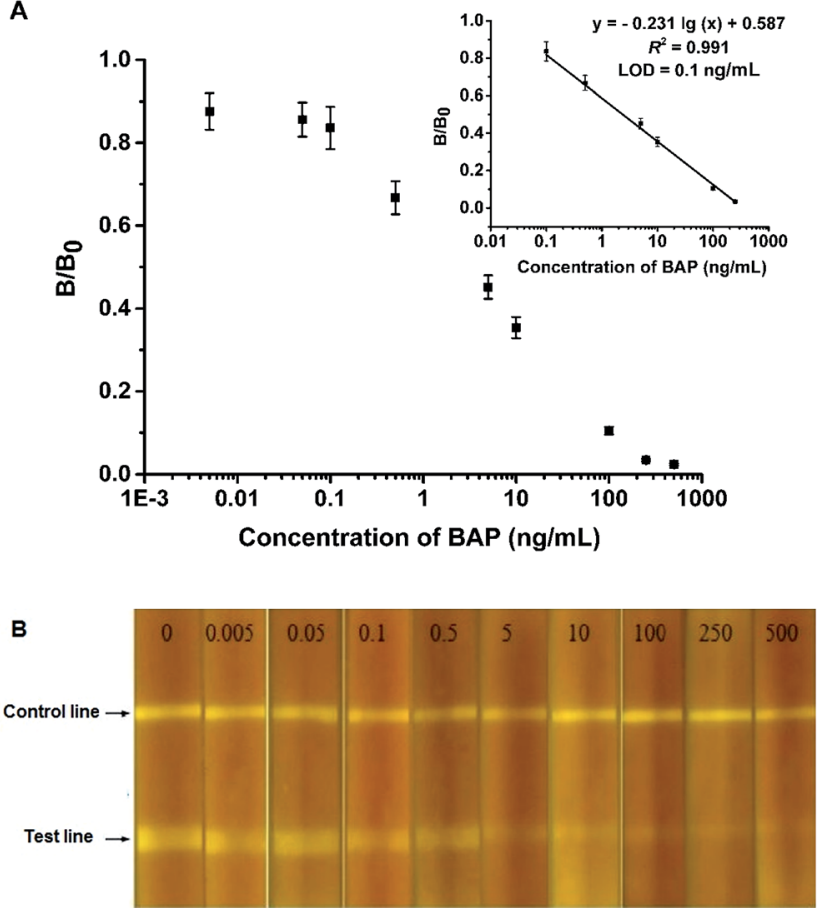

Fig. 5 Standard curve for BAP quantitative analysis and fluorescent pictures of the FM-LFIA test strip with a series of spiked concentrations $(0.000,0.005,0.050,0.100,0.500,5.000,10.000,100.000,250.000$, and $500.000 \mathrm{ng} \mathrm{mL}^{-1}$ ) in artificial serum. (A) The quantitative standard curve was constructed by plotting the $B / B_{0}$ ratio against the logarithm of different BAP concentrations. Data were obtained from three replicates. (B) Fluorescent pictures of the FM-LFIA test strip acquired under UV light with different BAP concentrations.

The concentration of BAP on the $\mathrm{T}$ line and the goat antimouse IgG on the $\mathrm{C}$ line were optimized through the orthogonal experiment with the measurement of positive samples $(2.0$ ng $\mathrm{mL}^{-1}$ ) (Table 2). The determination of optimal concentrations of BAP on the $\mathrm{T}$ line and goat anti-mouse IgG on the $\mathrm{C}$ line were also based on the $\mathrm{FI}_{\mathrm{T}} / \mathrm{FI}_{\mathrm{C}}$ ratio of the negative samples and the competitive inhibition ratio of the positive samples. As shown in Table 2, the maximum competitive inhibition ratio $(41.35 \%)$ and high $\mathrm{FI}_{\mathrm{T}} / \mathrm{FI}_{\mathrm{C}}$ ratio (0.841) were obtained at $2.0 \mathrm{mg}$ $\mathrm{mL}^{-1}$ of BAP on the $\mathrm{T}$ line and $0.25 \mathrm{mg} \mathrm{mL}^{-1}$ of goat anti-mouse IgG on the $\mathrm{C}$ line, respectively. Therefore, BAP $\left(2.0 \mathrm{mg} \mathrm{mL}^{-1}\right)$

Table 2 Optimization of the BAP concentration on the $T$ line and the goat anti-mouse IgG concentration on the $C$ line

\begin{tabular}{|c|c|c|c|c|c|}
\hline $\begin{array}{l}\text { Concentration of BAP } \\
\text { on the } \mathrm{T} \text { line }\left(\mathrm{mg} \mathrm{mL}^{-1}\right)\end{array}$ & $\begin{array}{l}\text { Concentration of } \\
\text { BAP on the } \mathrm{C} \text { line }\left(\mathrm{mg} \mathrm{mL} \mathrm{m}^{-1}\right)\end{array}$ & $\mathrm{FI}_{\mathrm{C}}$ & $\mathrm{FI}_{\mathrm{T}}$ & $\mathrm{FI}_{\mathrm{T}} / \mathrm{FI}_{\mathrm{C}}$ & $\begin{array}{l}\text { Competitive inhibition } \\
\text { ratio }(\%)\end{array}$ \\
\hline 1.0 & 0.10 & 256.67 & 135.44 & 0.529 & 12.09 \\
\hline 1.0 & 0.25 & 451.33 & 252.76 & 0.561 & 24.45 \\
\hline 1.0 & 0.50 & 518.33 & 251.18 & 0.485 & 32.78 \\
\hline 2.0 & 0.10 & 247.33 & 227.95 & 0.909 & 22.94 \\
\hline 2.0 & 0.25 & 463.00 & 388.85 & 0.841 & 41.35 \\
\hline 2.0 & 0.50 & 533.00 & 317.08 & 0.594 & 34.54 \\
\hline 4.0 & 0.10 & 240.33 & 220.00 & 0.915 & 19.49 \\
\hline 4.0 & 0.25 & 488.22 & 328.57 & 0.673 & 38.64 \\
\hline 4.0 & 0.50 & 499.00 & 246.05 & 0.493 & 26.32 \\
\hline
\end{tabular}


Table 3 The accuracy and precision of the FM-LFIA in BAP-spiked artificial serum

\begin{tabular}{|c|c|c|c|c|c|c|c|c|}
\hline $\mathrm{BAP}\left(\mathrm{ng} \mathrm{mL}^{-1}\right)$ & \multicolumn{4}{|l|}{ Intra-assay } & \multicolumn{4}{|l|}{ Inter-assay } \\
\hline 50 & 51.9 & 103.8 & 3.84 & 7.4 & 50.7 & 101.3 & 4.72 & 9.3 \\
\hline 150 & 151.1 & 100.7 & 12.84 & 8.5 & 138.6 & 92.4 & 9.98 & 7.2 \\
\hline
\end{tabular}

and goat anti-mouse IgG $\left(0.25 \mathrm{mg} \mathrm{mL}^{-1}\right)$ were sprayed onto the $\mathrm{NC}$ membrane as the $\mathrm{T}$ line and $\mathrm{C}$ line, respectively.

\subsection{Quantitative standard curve of the FM-LFIA test strip}

The relationships between the fluorescence intensity and the concentration of BAP were investigated under the optimized conditions. As shown in Fig. $5 \mathrm{~A}$, the $B / B_{0}$ had a good linear relationship with the BAP concentrations between $0.1 \mathrm{ng} \mathrm{\textrm {mL } ^ { - 1 }}$ and $250.0 \mathrm{ng} \mathrm{mL} \mathrm{m}^{-1}$. The regression equation could be matched as: $y=-0.231 \lg (x)+0.587, R^{2}=0.991$, where $y$ is the competitive inhibition ratio, $x$ is the concentration of BAP and $R$ is the regression coefficient. The calculated LOD was $0.1 \mathrm{ng}$ $\mathrm{mL}^{-1}$. Fig. 5B showed that the FM-LFIA test strip was placed under a UV-light with the excitation wavelength of $470 \mathrm{~nm}$. The picture indicated that fluorescence intensity on the $\mathrm{T}$ line changing from strong to weak with increasing concentration of BAP. However the FM-LFIA test strip could not be observed directly by naked eye without a UV-light.

\subsection{Specificity for BAP detection}

BAP, IALP, PALP, PA, HGB, and ALB were investigated via a comparison of results of competitive inhibition ratio at the same concentration of $500 \mathrm{ng} \mathrm{mL} \mathrm{m}^{-1}$ to evaluate the specificity of BAP detection. As demonstrated in Fig. S2, $\uparrow$ top to $96.7 \%$ of the competitive inhibition ratio was observed in the presence of BAP, whereas IALP, PALP, PA, HGB, and ALB showed lower competitive inhibition ratio compared with BAP. Thus, the results indicated the good specificity of the FM-LFIA for BAP.

\subsection{Accuracy and precision analysis}

Recovery experiments were conducted to evaluate the accuracy and precision of the FM-LFIA by using BAP-spiked artificial serum samples. The recovery and CVs of the intra- and interassay are shown in Table 3. The average recoveries for intraand inter-assays ranged from $98.6 \%$ to $103.8 \%$ and $92.4 \%$ to $111.5 \%$ with corresponding CVs of $6.7 \%$ to $8.5 \%$ and $4.6 \%$ to $9.3 \%$, respectively.

\subsection{Stability analysis of strips in the accelerated aging test}

Accelerated aging test was conducted at $60{ }^{\circ} \mathrm{C}$ for 13 days to evaluate the stability of the test strip (Fig. S3†). Research has proven that the accelerated aging test could estimate the stability of the LFIA test strip. ${ }^{45}$ According to the empirical Arrhenius equation $\left(K=A \times \mathrm{e}^{-E_{\mathrm{a}} / R T}\right)$, the stability of fluorescent signals in $25{ }^{\circ} \mathrm{C}$ for one year is equivalent to that in $60{ }^{\circ} \mathrm{C}$ for 3 days. ${ }^{46}$ The $\mathrm{FI}_{\mathrm{T}} / \mathrm{FI}_{\mathrm{C}}$ ratio of different concentrations of BAP did not significantly vary in the accelerated aging test at $60{ }^{\circ} \mathrm{C}$ for the first 6 days (Fig. S3†). Therefore, the test strips stored at $25{ }^{\circ} \mathrm{C}$ for 1 year can still be used for the detection of BAP.

\section{Conclusion}

A novel competitive FM-LFIA was constructed for rapid (15 min), sensitive, and quantitative detection of BAP. The optimal anti-BAP antibody with highest binding affinity to BAP was used for the detection of BAP. The FM-LFIA shows high sensitivity that was derived from the fluorescence detection technique and high binding affinity between BAP and anti-BAP Ab. Under optimal conditions, the LOD for the quantitative detection of BAP was $0.1 \mathrm{ng} \mathrm{mL}^{-1}$. The FM-LFIA can be used to detect BAP with better recovery and lower coefficient variation. The average recoveries for intra- and inter-assays ranged from $98.6 \%$ to $103.8 \%$ and $92.4 \%$ to $111.5 \%$ respectively, and the CVs for intraand inter-assay were below 10\%. The FM-LFIA test strip had good specificity for the detection of BAP and could still be used to detect the BAP when they were stored $25{ }^{\circ} \mathrm{C}$ for one year. The method for measurement of BAP is highly recommended for portable and rapid on-site detection in Point of Care Test application.

\section{Acknowledgements}

This study was financially supported by the Open Project Program of State Key Laboratory of Food Science and Technology of Nanchang University (SKLF-KF-201616) and the Free Explore Issue of State Key Laboratory of Food Science and Technology of Nanchang University (SKLF-ZZA-201612).

\section{References}

1 H. E. Takahashi, Clin. Calcium, 2011, 21, 520-527.

2 M. C. de Vernejoul, Drugs Aging, 1998, 12, 9-14.

3 H. Rief, G. Omlor, M. Akbar, T. Bruckner, S. Rieken, R. Förster, et al., BMC Cancer, 2016, 16, 1-7.

4 F. H. Glorieux, L. M. Ward, F. Rauch, L. Lalic, P. J. Roughley and R. Travers, J. Bone Miner. Res., 2002, 17, 30-38.

5 L. M. Ward, F. Rauch, R. Travers, G. Chabot, E. M. Azouz, L. Lalic, et al., Bone, 2002, 31, 12-18.

6 M. Zacharin and T. Cundy, J. Pediatr., 2000, 137, 410-415.

7 F. Rauch, R. Travers, M. E. Norman, A. Taylor, A. M. Parfitt and F. H. Glorieux, J. Bone Miner. Res., 2000, 15, 957-963. 
8 K. Mukaiyama, M. Kamimura, S. Uchiyama, S. Ikegami, Y. Nakamura and H. Kato, Aging: Clin. Exp. Res., 2015, 27, 413-418.

9 G. Çetin, A. E. Eşkazan, M. C. Ar, Ş. Ö. Aydın, B. Ferhanoğlu, T. Soysal, et al., Turk. J. Chem., 2014, 31, 374-380.

10 W.-X. Du, S.-F. Duan, J.-J. Chen, J.-F. Huang, L.-M. Yin and P.-J. Tong, J. Cancer Res. Ther., 2014, 10, 140-143.

11 E. Ishimura, S. Okuno, H. Okazaki, K. Norimine, K. Yamakawa, T. Yamakawa, et al., Kidney Blood Pressure Res., 2014, 39, 299-307.

12 J. Allgrove, J. Paediatr. Child Health, 2011, 5, 187-193.

13 K. J. Martin and E. A. González, J. Am. Soc. Nephrol., 2007, 18, 875-885.

14 J. M. Roudsari and S. Mahjoub, Caspian J. Intern. Med., 2012, 3, 478-483.

15 S. Mahjoub and J. M. Roudsari, J. Babol Univ. Med. Sci., 2006, 8, 34-39.

16 M. T. Parviainen, J. H. Galloway, J. H. Towers and J. A. Kanis, Clin. Chem., 1988, 34, 2406.

17 S. K. Hartwell, D. Somprayoon, P. Kongtawelert, S. Ongchai, O. Arppornchayanon, L. Ganranoo, et al., Anal. Chim. Acta, 2007, 600, 188-193.

18 F. Ahmed and S. M. Gibbons, J. Clin. Pathol., 2015, 68, 246248.

19 T. Peng, F. S. Zhang, W. C. Yang, D. X. Li, Y. Chen, Y. H. Xiong, et al., J. Food Prot., 2014, 77, 1824-1829.

20 J. H. W. Leuvering, P. J. H. M. Thal, M. V. D. Waart and A. H. W. M. Schuurs, J. Immunol. Methods, 1981, 45, 183-194.

21 Z. Wang, H. Li, C. Li, Q. Yu, J. Shen and S. S. De, J. Agric. Food Chem., 2014, 62, 6294-6298.

22 K. Hua, C. Xing, C. Hao, L. Liu, L. Wang and C. Xu, Sensors, 2013, 13, 4214-4224.

23 J. Y. Wang, M. H. Chen, Z. C. Sheng, D. F. Liu, S. S. Wu and W. H. Lai, RSC Adv., 2015, 5, 62300-62305.

24 X. Cui, Y. Huang, J. Wang, L. Zhang, Y. Rong, W. Lai, et al., RSC Adv., 2015, 5, 45092-45097.

25 D. Quesadagonzález and A. Merkoçi, Biosens. Bioelectron., 2015, 73, 47-63.

26 D. Liu, Z. Yu, Y. Huang, S. Wang, J. Wang, Q. Guo, et al., J. Nanosci. Nanotechnol., 2016, 16, 2291-2595.

27 X. Zhang, J. Zhou, C. Zhang, D. Zhang and X. Su, RSC Adv., 2015, 6, 1279-1287.
28 A. Foubert, N. V. Beloglazova and S. S. De, Anal. Chim. Acta, 2016, 955, 48-57.

29 Y. Zhao, C. Zhou, R. Wu, L. Li, H. Shen and L. Li, RSC Adv., 2014, 5, 5988-5995.

30 L. M. Hu, K. Luo, J. Xia, G. M. Xu, C. H. Wu, J. J. Han, et al., Biosens. Bioelectron., 2017, 91, 95-103.

31 X. Zhang, K. Wen, Z. Wang, H. Jiang, R. C. Beier and J. Shen, Food Control, 2016, 60, 588-595.

32 S. Nankoberanyi, G. W. Mbogo, N. P. Leclair, M. D. Conrad, P. Tumwebaze, S. Tukwasibwe, et al., Malar. J., 2014, 13, 95100.

33 J. L. Wilson, I. M. Scott and J. L. McMurry, Biochem. Mol. Biol. Educ., 2010, 38, 400-407.

34 A. Mechaly, H. Cohen, O. Cohen and O. Mazor, Anal. Biochem., 2016, 506, 22-27.

35 C. A. Wartchow, F. Podlaski, S. Li, K. Rowan, X. Zhang, D. Mark, et al., J. Comput.-Aided Mater. Des., 2011, 25, 669676.

36 Y. Yang, C. Li, W. Wang, T. Dong, Y. Xiong, J. Shen, et al., Anal. Methods, 2015, 7, 8683-8688.

37 S. L. Deng, S. Shan, C. L. Xu, D. F. Liu, Y. H. Xiong, H. Wei, et al., J. Food Prot., 2014, 77, 1998-2003.

38 Q.-Y. Xie, Y.-H. Wu, Q.-R. Xiong, H.-Y. Xu, Y.-H. Xiong, K. Liu, et al., Biosens. Bioelectron., 2014, 54, 262-265.

39 L. Anfossi, C. Baggiani, C. Giovannoli, F. Biagioli, G. D'Arco and G. Giraudi, Anal. Chim. Acta, 2013, 772, 75-80.

40 M. Cummins, C. Dogovski, R. Robert, M. Alderton, D. Chong, D. Proll, et al., Antibodies, 2014, 3, 215-231.

41 N. P. Tal, R. Ronit, A. Naomi, E. Eyal, A. Ron, Z. Anat, et al., Toxins, 2016, 8, 64-79.

42 Y. B. Miao, H. X. Ren, N. Gan, Y. Cao, T. Li and Y. Chen, Biosens. Bioelectron., 2016, 81, 454-459.

43 Y. Chen, Y. Xin, H. Yang, L. Zhang, Y. Zhang, X. Xia, et al., Int. J. Biol. Macromol., 2013, 56, 6-13.

44 H. Duan, X. Chen, W. Xu, J. Fu, Y. Xiong and A. Wang, Talanta, 2015, 132, 126-131.

45 W. Jawaid, K. Campbell, K. Melville, S. J. Holmes, J. Rice and C. T. Elliott, Anal. Chem., 2015, 87, 5324-5332.

46 Y. Wang, H. Xu, M. Wei, H. Gu, Q. Xu and W. Zhu, Mater. Sci. Eng., C, 2009, 29, 714-718. 